\title{
Tense in Temporal Adjunct Clauses
}

\author{
Ana Arregui \\ Kiyomi Kusumoto \\ HIL, Leiden University/ \\ University of Massachusetts, Amherst \\ University of Massachusetts, Amherst
}

The behaviour of tense in subordinate clauses is not uniform across languages and theories that deal with the interpretation of tense try to explain this. The interpretation of past and present tense in complement clauses is one of the well known puzzles. Languages differ on this respect, and have been classified accordingly as sequence of tense languages (e.g. English) and non-sequence of tense languages (e.g. Japanese). In this paper we will be concerned mainly with the interpretation of tenses in temporal adjunct clauses (TACs). We will discuss the analysis proposed by Ogihara [1994, 1996] and argue that the differences in tense distribution that we observe between English and Japanese TACs are not to be explained as a case of sequence of tense.

\section{Tense in Complement Clauses and the Relative Tense Hypothesis}

Example (1) below illustrates a case of "sequence of tense" (SOT) in English. As is well known, the sentence is ambiguous. In the "simultaneous reading" [Enç 1987], it reports that at some point in the past Bemhard said that Junko was sick at the moment that he was speaking (i.e. (2a)). In the "past shifted reading", it reports that Bernhard said that Junko had been sick at some previous time (i.e. (2b)):

(1) Bernhard said that Junko was sick.

(2) a. Bernhard said: "Junko is sick".

b. Bernhard said: "Junko was sick".

What is typical of SOT-languages like English is that an embedded past tense can be used to report a past present tense utterance. If we interpret (1) as a report of (2a). the reported event is understood to have been simultaneous with the matrix clause event

In non-SOT-languages, like Japanese, the simultaneous interpretation is not available for a past tense in a complement clause: (3) can only be interpreted as reporting an event that temporally precedes the matrix clause event.

$$
\begin{aligned}
& \text { Bernhard-wa [Junko-ga byooki-datta to] itta. } \\
& \text { B-top J-nom sick-be-past comp say-past } \\
& \text { 'Bernhard said that Junko had been sick' }
\end{aligned}
$$


In order to obtain the simultaneous interpretation we noted for (1), in Japanese a present tense must be used in the embedded clause, as in (4).

$$
\begin{aligned}
& \text { Bernhard-wa [Junko-ga byooki-da to] itta. } \\
& \text { B- top J-nom sick-be-pres comp say-past } \\
& \text { 'Bernhard said that Junko was sick' }
\end{aligned}
$$

To explain the ambiguity in (1) and the lack of ambiguity in (3), Ogihara [1989, 1995a, 1996] makes the proposal we briefly sketch here: Tenses in matrix clauses are absolute: they take the speech time $\left(\mathrm{s}^{*}\right)$ as reference time. Tenses in complement clauses are relative: they are interpreted in the scope of the matrix tense and take the temporal location of the matrix clause event as reference time. The result is that a past tense in a complement clause orders an event with respect to the matrix clause event, not with respect to the speech time.

As examples (1) and (3) illustrate, there is crosslinguistic variation regarding the interpretation of past tense complement clauses. Ogihara proposes to account for it in terms of variation regarding the presence or absence of an SOT-rule that deletes tenses at LF. SOT-languages, like English, have such a rule, and non-SOT-languages, like Japanese, lack it. In order for the SOT-rule to apply, a tense must be c-commanded by an identical tense at LF. The application of this rule to the English example in (1) results in an LF as in (1'):

(1') a. Bernhard say-Past that Junko be- $\varnothing$ sick.

b. $\exists \mathrm{t}\left[\mathrm{t}<\mathrm{s}^{*} \& \operatorname{say}\left(\lambda \mathrm{t}^{\prime}\left[\operatorname{sick}(\operatorname{Junko})\left(\mathrm{t}^{\prime}\right)\right]\right)(\right.$ Bernhard $\left.)(\mathrm{t})\right]$

Once the SOT-rule has applied, the embedded past tense is deleted and the resulting LF is given the semantic representation in ( 1 'b) where the embedded tenseless sentence is interpreted as a property of times. The application of the SOT-rule in English is optional: if it applies, as in (1'), we obtain the simultaneous reading; if it doesn't apply, then both past tenses are present at LF and we obtain the past shifted reading.

Non-SOT-languages, like Japanese, do not have an SOT-rule. Therefore both past tenses are present in the LF representation of (3), and only the past shifted reading is possible. The simultaneous reading can only be rendered by an embedded present tense as in (4).

\section{Temporal Adjunct Clauses (TACs)}

The literature on sequence of tense has mainly been concerned with the interpretation of tense in complement and relative clauses. Ogihara [1994. 1996] proposes to extend the relative tense analysis to tenses in TACs. According to ()gihara, tenses in TACs are semantically in the scope of the matrix tense. It is the matrix clause event time, not the speech time, that functions as the reference 
time of the embedded tense. Evidence for a relative tense analysis of tenses in TACs comes mainly from Japanese before- and after-clauses.

\subsection{Distribution of tense in Japanese before-and after-clauses}

In Japanese, tense in before-clauses is obligatorily a present tense:
a. *[Junko-ga kita mae-ni] Satoshi-wa kaetta
J.-nom come-past before S.-top leave-past
b. Junko-ga kuru mae-ni] Satoshi-wa kaetta J.-nom come-pres before S.-top leave-past 'Satoshi left before Junko came'

According to Ogihara the contrast in (5) can be explained by a relative tense analysis of TACs. If the matrix clause event time functions as the reference time of the embedded tense, then the embedded tense will order the TAC event with respect to the matrix clause event. The restrictions on tense distribution then follow from the fact that we expect the information given by tense in the TAC to be compatible with the temporal relation established by the temporal connective in the TAC.

Let us consider a relative tense analysis of the example above: in (5a) the embedded tense is past, and defined with respect to the matrix clause event time, it establishes a relation of anteriority between the TAC event and the one referred to by the matrix clause. But this contradicts the information given by before, and according to Ogihara the unacceptability of (5a) is due to this incoherence. What about $(5 \mathrm{~b})$ ? A present tense in Japanese can receive a future interpretation.' The present tense in the adjunct clause in $(5 \mathrm{~b})$ is interpreted as indicating that the TAC erent is future with respect to the matrix clause event. Therefore in (5b) the information given by tense is compatible with the information provided by the temporal connective. Both the embedded tense and before indicate that the TAC event takes place at some time in the future with respect to the matrix clause event (it need not be future with respect to the speech time). The scheme below illustrates the temporal relations established by the embedded tenses in ( $5 \mathrm{a}$ ) and (5) $)$ :

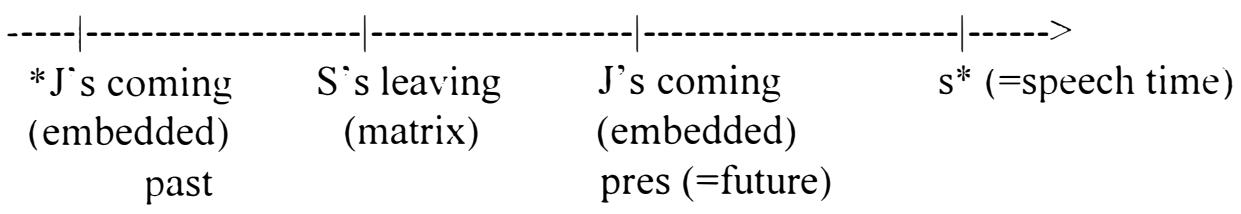

If the temporal connective in the TAC is after instead of before, the restrictions on tense differ: 

a. [Junko-ga kita ato-ni] Satoshi-wa kaetta
J.-nom come-past after S.-top leave-past
'Satoshi left after Junko came'
b. * [Junko-ga kuru ato-ni] Satoshi-wa kaetta J.-nom come-pres after S.-top leave-past

Again this is to be expected if we allow tense in the TAC to be defined with respect to the matrix clause event time. The past tense in (6a) indicates that the TAC event is past with respect to the matrix clause event, and this is compatible with the meaning of after. The present tense in (6b) indicates that the TAC event is future with respect to the matrix clause event, and this contradicts the meaning of after. The temporal relations are illustrated in the scheme below:

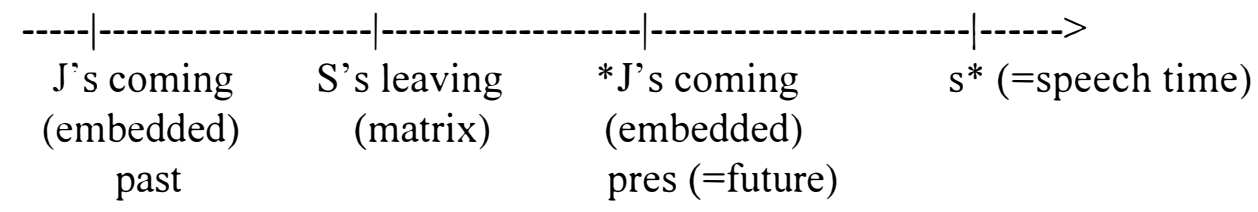

By characterizing tense in TACs as a relative tense that takes the matrix clause event time as reference time, Ogihara's hypothesis is able to account for the restrictions on tense distribution in Japanese before- and after-clauses with the simple requirement that the information given by tense be consistent with the information given by the temporal connective. ${ }^{2}$

\subsection{Distribution of tense in English before-and after-clauses}

The distribution of tense in English TACs is different than in Japanese. As is illustrated below, a past tense is possible both in before- and after-clauses:

a. Elliott left before Eva came.

b. Elliott left after Eva came.

According to Ogihara, the crucial difference between English and Japanese, that explains why a past tense is acceptable in (7a) and is not possible in (5a), is that English is an SOT-language, and has an SOT-rule. Once the SOT-rule has applied to examples like (7), we obtain the LFs illustrated in ( $\left.7^{\prime}\right)$ :

$\left.7^{\circ}\right)$ a. Elliott leave-Past before Eva come- $\varnothing$.

b. Elliott leave-Past after Eva come- $\varnothing$.

A fter the application of the SOT-rule at LF, English before- and after-clauses are tenseless. As a result, the only order established between the events is the order 
given by the temporal connective. The reason that no conflict arises between the information provided by tense and that established by before in (7a) is that the SOT-rule in English allows tense to be deleted at LF.

\section{Difficulties for a relative tense analysis}

In this section we will discuss some difficulties for a relative tense account of the interpretation of tense in TACs. Partly the problems come from Japanese itself, we will see in section 3.1 that some TACs in Japanese do not follow the pattern to be expected under a relative tense analysis. Furthermore we will see in section 3.2 that not all non-SOT languages follow the Japanese pattern in before- and cifter-clauses.

\subsection{Distribution of tense in Japanese when-clauses}

The distribution of tense in Japanese when- clauses is unexpected from the perspective of a relative tense analysis. The temporal connective toki 'when' establishes a relation of simultaneity between events, and yet a past tense is possible in when-clauses:

$$
\begin{aligned}
& \text { [Satoshi-ga kita toki] Junko-wa heya-ni ita } \\
& \text { S.-nom come-past when J.-top room-at be-past } \\
& \text { 'Junko was in her room when Satoshi came' }
\end{aligned}
$$

Since Japanese has no SOT-rule, Ogihara's proposal predicts (8) to be unacceptable for reasons that are similar to his explanation of (5a) and (6b): the embedded past tense in (8) locates the TAC event to the past of the matrix clause event and this contradicts the information supplied by the temporal connective, which indicates that the events are simultaneous.

Interestingly, present tense when- clauses are possible in Japanese:

[Satoshi-ga kuru toki] Junko-wa heya-ni ita S.-nom come-pres when J.-top room-at be-past

'Junko was in her room when Satoshi came' (quantificational/habitual)

The present tense TAC in (9) receives a habitual reading: we interpret (9) as reporting that Junko was in her room whenever Satoshi came. The difference between past tense (8) and present tense (9) is a difference in quantificational strength: (8) receives an episodic interpretation and (9) a habitual one. Examples like (8) and (9) therefore raise two questions: why is a past tense acceptable at all, and why is there a quantificational rather than temporal difference between past and present. 


\subsection{Distribution of tense in Polish before-and after-clauses}

Polish. as Japanese, is a non-SOT-language. In complement clauses a past tense embedded under a past tense establishes a relation of anteriority between the embedded clause event and the matrix one. A relation of simultaneity is indicated by an embedded present tense. This is illustrated by (10a) and (10b) below. A future tense embedded under a past tense follows the same pattern: in (10c) the embedded future tense takes the matrix clause event time as reference time and locates the time of the event to the future of the matrix clause event:

a. Ania powiedziała, ze Marcin jest chory.

Ania say-prf-past that Marcin be-pres sick

'Ania said that Marcin was sick' (= Ania said: "Marcin is sick")

b. Ania powiedziała, ze Marcin był chory.

Ania say-prf-past that Marcin be-past sick

'Ania said that Marcin had been sick'(= Ania said: "Marcin was sick")

c. Ania powiedziała, ze bẹdzie padać.

Ania say-prf-past that fut rain

'Ania said that it would rain'

Having established the similarity between Polish and Japanese regarding the behaviour of tenses in complement clauses, let us now look at Polish TACs:

a. Ania przyszła na przyjęcie zanim Marcin przysedt.

Ania prf-come-past to party before Marcin prf-come-past

'Ania came to the party before Marcin left'

b. * Ania przyszła na przyjeccie zanim Marcin przychodzi.

Ania prf-come-past to party before Marcin prf-come-pres

c. * Ania przyszła na przyjęcie zanim Marcin przyjdzie.

Ania prf-come-past to party before Marcin prf-come-fut

Interestingly, Polish TACs follow the English pattern, not the Japanese one. As (11) shows a past tense is obligatory with before-clauses. But Polish is not an SOT-language and the past tense in (11a) will not be deleted at LF. So the fact that $(11 \mathrm{a})$, and not $(11 \mathrm{~b}$ or $\mathrm{c})$, is acceptable, argues against the idea that tenses in TACs take the matrix clause event time as reference time. ${ }^{3}$

\section{Crosslinguistic variation regarding TACs}

We will argue against a relative tense account of the interpretation of tense in TACs and propose instead that tenses in English and Polish TACs are interpreted as absolute tenses: they take the speech time as reference time independently of the matrix tense. We will follow Geis [1970] and Larson [1990] in analysing 
English TACs as relative clauses. This analysis is supported by the presence of ambiguities discussed by Geis [1970], and we will extend it to Polish TACs.

We will propose that Japanese before- and after-clauses involve less structure than their English and Polish counterparts and are not interpreted as relative clauses. This is borne out by the absence of ambiguities of the type discussed by Geis. We will suggest that the restrictions on tense distribution are due to a difference in quantificational strength between Japanese past and present tense. We will provide evidence for this proposal by examining the interpretation of Japanese when-clauses.

\subsection{Tense interpretation in root clauses}

There has been a debate as to how tense contributes to the truth conditions of sentences. In the tradition of tense logic [Prior 1967], tense is considered to be a sentential operator. Past tense, for instance, is an operator that shifts the evaluation time to the past. As an alternative to this proposal, Partee [1973] shows that tenses and pronouns have much in common, suggesting that tenses themselves are referential expressions that denote times and are interpreted in a fashion similar to pronouns.

We would like to propose that languages have mixed systems, with some tenses functioning as operators and others as temporal variables. Tenses that function as temporal variables lack quantificational force of their own and may be bound. We will propose that in both English and Japanese there is a present tense variable and a past tense operator.

Let us begin with a few assumptions. For the sake of simplicity, we will adopt the VP internal subject hypothesis, and subjects will be put back in their original VP internal position. We assume that predicates have an extra argument slot for a time variable. Tenses project a tense phrase (TP), and are realized under its head. Under these assumptions, simple present and past tense sentences will be interpreted as in (12) and (13):

a. John is sick

b.

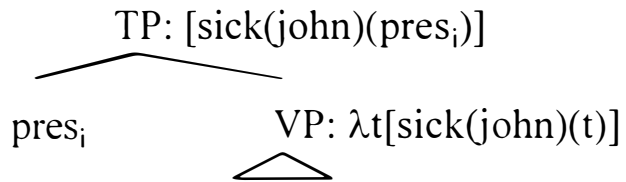

John be sick

The unbound present tense variable in $(12 b)$ is interpreted as indexical: the sentence means that John is sick at the moment of the speech. 
a. John was sick

b. $\quad C P: \exists \mathrm{t}^{\prime}\left[\mathrm{t}^{\prime}<\mathrm{s} * \& \operatorname{sick}(\mathrm{john})\left(\mathrm{t}^{\prime}\right)\right]$

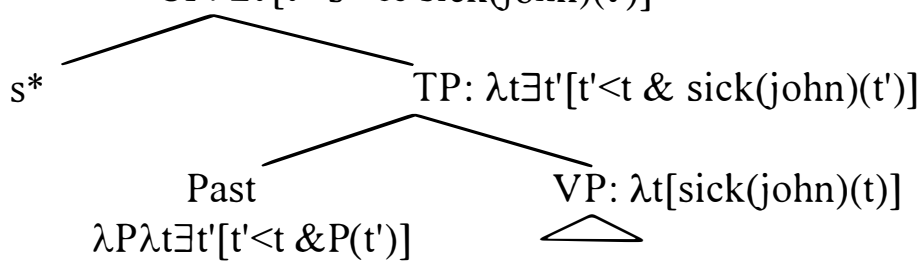

John be sick

The past tense in (13) is a Priorian operator which introduces an existential quantifier over times and shifts the event time into the past. The TP denotes a set of times after which John is sick. The speech time $\mathrm{s}^{*}$ is overtly realized in syntax in $\mathrm{C}$. When evaluated with respect to the speech time, the sentence is true iff there exist a time before the speech time at which John is sick.

\subsection{Relative clause analysis of English when-clauses (Geis [1970])}

In this section we will introduce the relative clause analysis of TACs. We begin with an observation from Geis [1970]. He noted that complex English whenclauses, as (14), are ambiguous.

\section{(14) I encountered Satoshi in Amherst when you said he had left}

For instance, suppose that I met you in Amherst at 3:00 p.m., and you said, "Satoshi left here at 10:00 a.m. this morning". On the "upstairs" reading, the time that I met him is the time of your speech. namely, 3:00 p.m. On the "downstairs" reading, the time I met him is the time of Satoshi's leaving according to you, namely, 10:00 a.m. Geis argues that this ambiguity can be captured by analyzing when-clauses as relative clauses. The two readings of the sentence in (14) can be represented as follows.

(15) a. I encountered Satoshi in Amherst at a time which ${ }_{i}$ you said at $t_{i}$ [he had left]

b. I encountered Satoshi in Amherst at a time which i $_{\mathrm{i}}$ you said [he had left at $t_{i}$ ]

In (15a) which is extracted out of the TAC's main clause, giving rise to the reading in which when relates the time of my meeting and the time of your speech. In (15b), extraction is out of the TAC's embedded clause. resulting in the reading in which the time of my meeting is compared with the time of Satoshi's leaving.

The example below illustrates our implementation of the relative clause analysis of TACs. The relative pronoun is moved from the complement position 
of the preposition at to the embedded Spec-CP. The index on the pronoun functions as an abstractor over the trace that is left behind. (See Heim and Kratzer [1997])

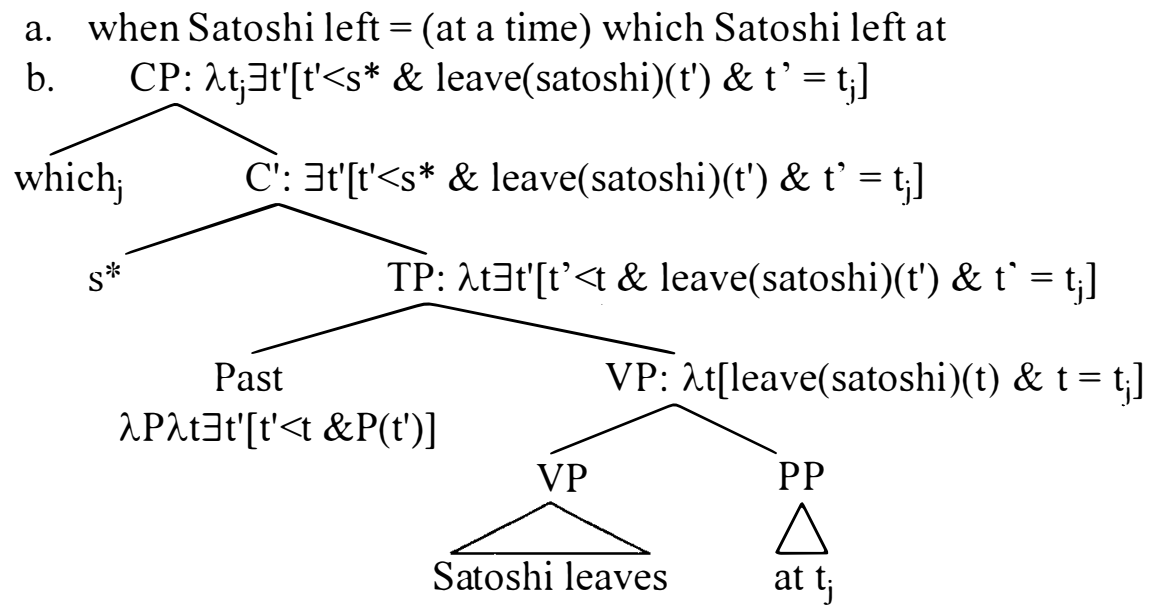

Notice that the speech time appears in $\mathrm{C}$ in this structure and the past tense operator orders the TAC event with respect to $\mathrm{s}^{*}$. In complex when-clauses, the relative pronoun may be extracted either from the higher (15a) or most embedded clause (15b), giving rise to the observed ambiguity.

From here on, the compositional interpretation of sentences containing when-clauses goes as follows: when- clauses (and TACs in general) are VP modifiers. The denotation of the resulting structure is the intersection of the VP denotation and the corresponding TAC denotation as shown below:

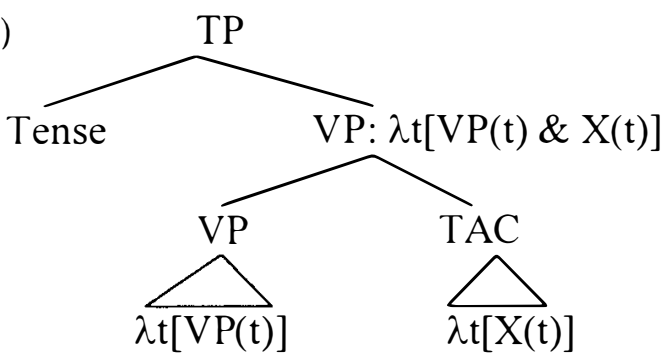

The relative clause analysis we are proposing ensures that, although when-clauses are syntactically in the scope of the matrix tense, tenses embedded in whenclauses are not semantically in the scope of the matrix tense. Similarly to tenses in matrix clauses, tenses in when-clauses are interpreted as absolute tenses. taking the speech time as reference time.

\subsection{Before- and after-clanses}

In this section we will discuss the interpretation of tense in before- and after- 
clauses. English and Polish before- and after-clauses evidence the same kind of ambiguities as English when- clauses, and we will follow Geis [1970] and Larson [1990] and suggest that they should also be analysed as relative clauses. Correspondingly, tenses will be construed independently, taking the speech time as reference time. Japanese before- and after-clauses, on the other hand, are not ambiguous, indicating that a different analysis is necessary.

\subsection{1. 'Before ' and 'After'}

Before turning to the differences between English/Polish and Japanese, we will say a few words about the denotations of before and after. It has been noted in Anscombe [1964], Landman [1991] and Ogihara [1995] among others that there are differences between before and after that cannot be reduced to temporal differences. Compare the following examples:
a. I watered the plant before it died
b. I watered the plant after it died

There is a difference in veridicality between (18a) and (18b). We can interpret the hefore-clause in (18a) as describing a state of affairs that did not actually take place. In this interpretation the plant did not die. But we can only interpret the after-clause in (18b) as referring to a state of affairs that did come to pass.

The following denotations have been proposed to account for this difference:

$$
\begin{aligned}
& \text { before }=\lambda \mathrm{P} \lambda \mathrm{t} \forall \mathrm{t}^{\prime}\left[\mathrm{P}\left(\mathrm{t}^{\prime}\right) \rightarrow \mathrm{t}<\mathrm{t}^{\prime}\right] \\
& \text { after }=\lambda \mathrm{P} \lambda \mathrm{t}^{\prime} \exists \mathrm{t}^{\prime}\left[\mathrm{t}^{\prime}<\mathrm{t} \& \mathrm{P}\left(\mathrm{t}^{\prime}\right)\right]
\end{aligned}
$$

According to (19) a before- clause refers to a set of times which are not after a Ptime. This in itself does not require that there exist a P-time and correctly captures the non-factual interpretation of before-clauses. On the other hand afterclauses do require that the embedded-clause event actually take place, and this is also captured by (19). ${ }^{4}$

\subsubsection{Before- and after-clauses in English and Polish}

The ambiguities noted in English when- clauses arise also in English beforeand after-clauses, and this has led Geis and Larson to extend the relative clause analysis to these cases too. (21) illustrates how the ambiguity of (20a) is derived in our implementation of the analysis:

(2) a. I encountered Satoshi in Amherst after you said he had left

b. Anita left before she said she had 
(21) a. I encountered Satoshi in Amherst after a time whichi you said at $\mathrm{t}_{\mathrm{i}}$ [he had left]

b. I encountered Satoshi in Amherst after a time whichi you said [he had left at $t_{i}$ ]

Polish before- and after-clauses -as (22)- show the same ambiguities as their English counterparts, suggesting that the same analysis should be extended to these cases:

(22) a. Widziałem Lize, po tym jak powiedziała, ze jej nie bẹdzie. see-perf-past Lisa after this how say-perf-past that her not be-fut '(I) saw Lisa after (she) said she would leave'

b. Widziałem Lizẹ zanim powiedziała, ze jej nie bẹdzie. see-perf-past Lisa before say-perf-past that her not be-fut '(I) saw Lisa before (she) said she would leave'

Following up on Larson's analysis, we propose that English and Polish TACs have the structure in (23):

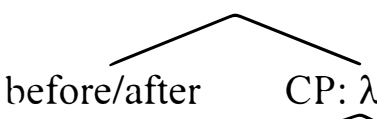

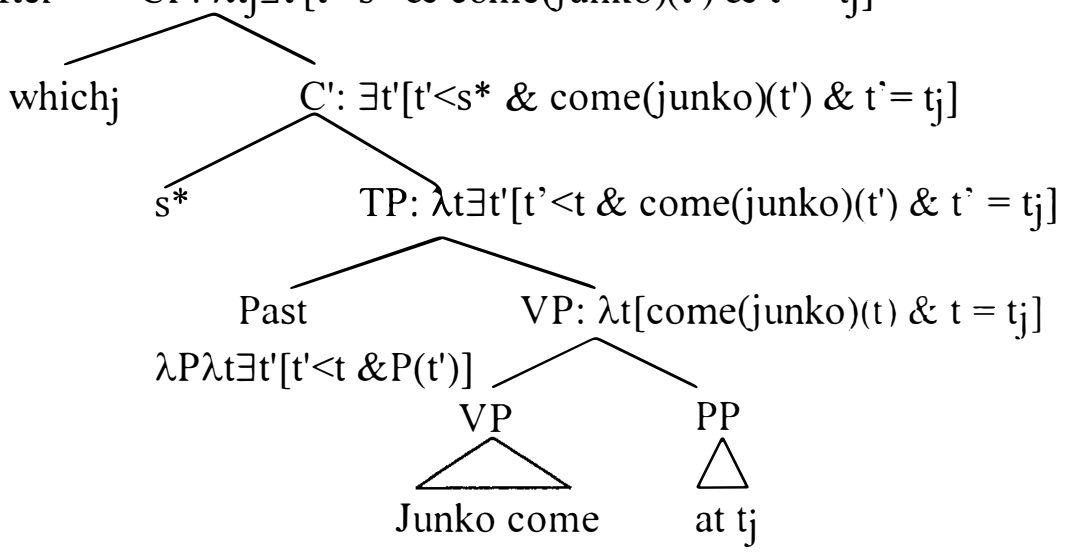

The semantic representations of before- and after-sentences is given below.

(24) a. Satoshi left after Junko came

b. $\exists \mathrm{t}^{\prime}\left[\mathrm{t}^{\prime}<\mathrm{s} *\right.$ \& leave(satoshi)(t') \& $\exists \mathrm{t}^{\prime \prime}\left[\mathrm{t}^{\prime \prime}<\mathrm{s} * \&\right.$ come $\left.\left.(j u n k o)\left(\mathrm{t}^{\prime \prime}\right) \& \mathrm{t}^{\prime \prime}<\mathrm{t}^{\prime}\right]\right]$

(25) a. Satoshi left before Junko came

b. $\exists \mathrm{t}^{\prime}\left[\mathrm{t}^{\prime}<\mathrm{s}^{*} \&\right.$ leave( $\left.\operatorname{satoshi}\right)\left(\mathrm{t}^{\prime}\right) \&$

$$
\left.\forall \mathrm{t}^{\prime \prime}\left[\mathrm{t}^{\prime \prime}<\mathrm{s}^{*} \& \text { come }(\mathrm{junko})\left(\mathrm{t}^{\prime \prime}\right) \rightarrow \mathrm{t}^{*}<\mathrm{t}^{\prime \prime}\right]\right]
$$

In both (24) and (25) the embedded tense orders the TAC event with respect to the speech time. There is no relation between the matrix tense and the 
embedded tense. The order between the events is established solely by the temporal connective.

\subsubsection{Before- and after-clauses in Japanese}

A striking difference between English/Polish and Japanese is that the ambiguity in TACs we discussed above does not show up in Japanese beforeand after-clauses.

(26) a. Junko-wa [zibun-ga [kaeru to] itta ato-de kaetta. J-top self-nom leave-pres comp say-past after leave-past 'Junko left after she said she would'

b. Watasi-wa Satoshi-ni [anata-ga [kaetta to] iu mae-ni] I-top S-dat you-nom leave-past comp say-pres before Amherst-de atta.

Amherst-in meet-past

'I encountered Satoshi in Amherst before you said (he) had left'

The sentences in (26) only have the upstairs reading: (26a) tells us that Junko left after she spoke and (26b) that I met Satoshi before you spoke. The lack of ambiguity indicates that the relative clause strategy is not available for the interpretation of Japanese before- and after- clauses. We would like to propose that before and after in Japanese select TP directly, and that it is in this respect that they differ from their English and Polish counterparts. Given our assumptions so far, the structure of after- clauses will be as in (27):

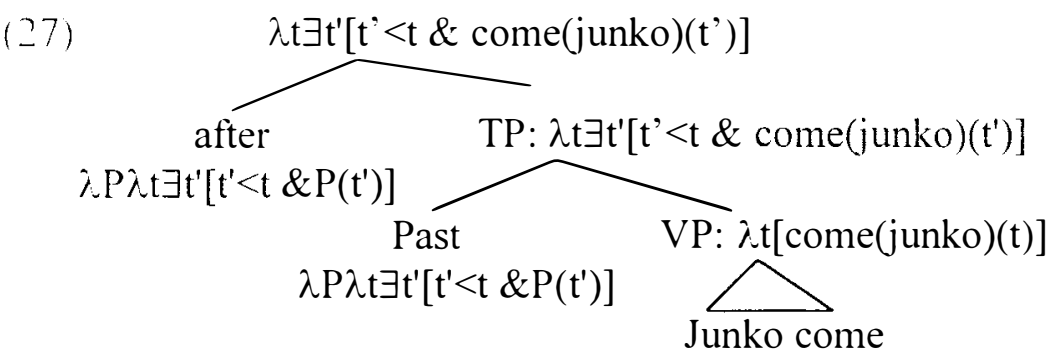

If hefore and after select TP. $\mathrm{s}^{*}$ cannot appear in the complement of the temporal connective. If it did appear, somewhere other than in $\mathrm{C}$. the result would simply be uninterpretable: both before and after semantically require the complement to be a set of times, i.e., of type $<i, t>$, but the speech time. when combined with the TP, results in a truth value.

Given the structure in (27) and our assumptions so far. after-clauses are interpreted as in (28b): 
(28)
a. [Junko-ga kita ato-ni] Satoshi-wa kaetta
J-nom come-past after S-top leave-past
'Satoshi left after Junko came'
b. $\exists \mathrm{t}^{\prime}\left[\mathrm{t}^{\prime}<\mathrm{s} * \&\right.$ leave( $\left.\operatorname{satoshi}\right)\left(\mathrm{t}^{\prime}\right) \& \exists \mathrm{t}^{\prime \prime}\left[\right.$ come $\left.\left.(j u n k o)\left(\mathrm{t}^{\prime \prime}\right) \& \mathrm{t}^{\prime \prime}<\mathrm{t}^{\prime}\right]\right]$

Let us now look at before- clauses in Japanese. Given the denotation of hefore we have adopted, the truth conditions of (29a) will be (29b).
a. [Junko-ga kuru mae-ni] Satoshi-wa kaetta J-nom come-pres before S-top leave-past 'Satoshi left before Junko came'
b. $\exists \mathrm{t}^{\prime}\left[\mathrm{t}^{\prime}<\mathrm{s}^{*} \&\right.$ leave( $\left.\left.\left.\operatorname{satoshi}\right)\left(\mathrm{t}^{\prime}\right) \& \forall \mathrm{t}^{\prime \prime}\left[\operatorname{come}(j u n k o)\left(\mathrm{t}^{\prime \prime}\right)\right] \rightarrow \mathrm{t}^{\prime}<\mathrm{t}^{\prime \prime}\right]\right]$

We have seen that before- clauses in Japanese only allow present tense complements. We would like to argue that this restriction is due both to lexical properties of before and to the nature of the present tense. We propose to treat before in Japanese as a quantificational element. It must bind some object-language variable. In our analysis, this is captured by the stipulation that before is lexically specified as bearing a binder index. The present tense, we have suggested, functions as a temporal variable. Given these two proposals, the logical representation in (29b) is derived from the LF in (30):

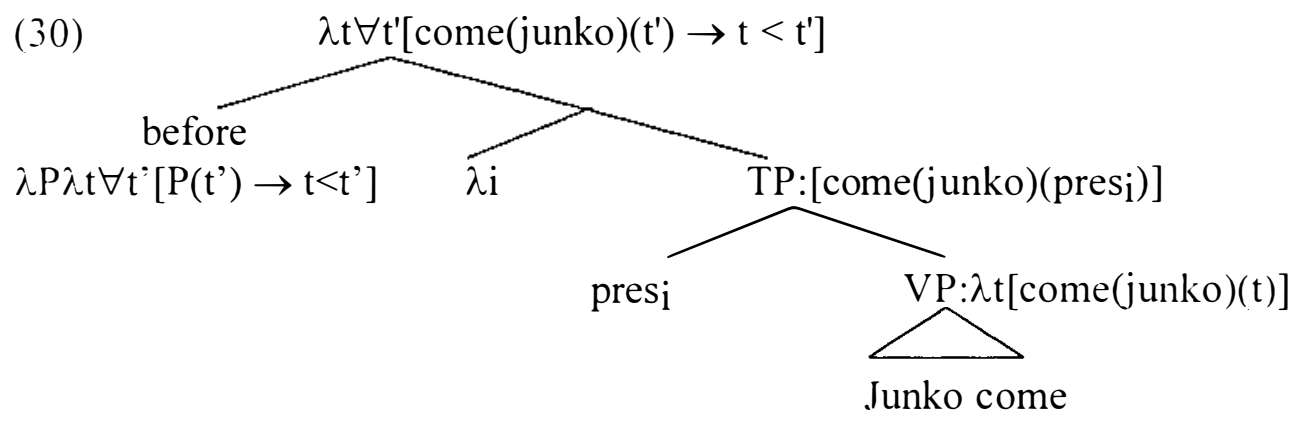

In the next section we will see evidence supporting an analysis of the present tense in Japanese as a temporal variable. We have no independent evidence in lilvour of a lexical distinction between before and after in Japanese in terms of binding possibilities. 5

\subsection{Variables and operators: the interpretation of when-clanses in .Japanese}

In this section we will support the analysis proposed above by presenting evidence in favour of a characterization of the present tense in Japanese as a temporal variable. To do so we will come back to the present/past contrast in the interpretation of when-clauses. We have seen in section 3.1 that (31) raises two questions. The first is about the grammaticality of (31a) and the 
second about the interpretation of (31b).
a. [Satoshi-ga kita
toki] Junko-wa heya-ni ita
S.-nom come-past when J.-top room-at be-past
"Junko was in her room when Satoshi came"
b. [Satoshi-ga kuru toki] Junko-wa heya-ni ita
S.-nom come-pres when J.-top room-at be-past
'Junko was in her room whenever Satoshi came'

We will see in this section that the facts in (31) follow quite straightforwardly once we make a distinction between past and present tense in terms of quantificational strength: in our analysis past tense will be characterized as an operator, with its own quantificational force, and present tense as a variable, devoid of quantificational force. The facts in (31) will therefore provide support in favour of our suggestion that the reason that a present tense is obligatory in Japanese before-clauses is that it can function as a bound variable, while a past tense cannot.

\subsubsection{A past tense operator and the episodic interpretation of when-clauses}

It is implausible to suggest that a past tense in when-clauses takes the matrix clause event time as reference time. The result would be incompatible with the meaning of when. Instead we propose to treat the past tense operator in whenclauses as an absolute tense, that takes the speech time as reference time. Under this analysis, Japanese when- clauses are similar to English when- clauses and different from Japanese before- and after- clauses. Since we associate the availability of the independent interpretation of tense with a relative clause analysis of TACs, we expect Japanese when- clauses to show Geis-type ambiguities, even though Japanese before- and after-clauses do not. The example below shows that these ambiguities do in fact arise:

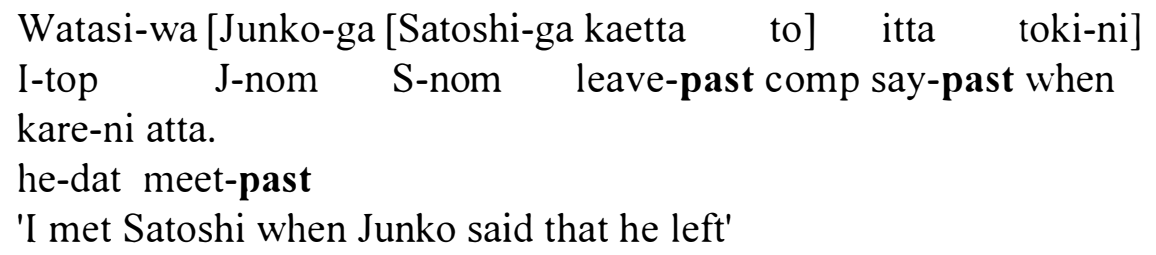

We can interpret (32) either as saying that I met Satoshi at the time that Junko spoke or at the time at which, according to Junko, he left.

Having given evidence in favour of a relative clause analy'sis, we propose to derive the interpretation of (33a) as in the English examples we considered in section 4.2.. resulting in the representation in $(33 \mathrm{~b})$ : 
(33) a. [Satoshi-ga kita toki] Junko-wa heya-ni ita S-nom come-past when J-top room-at be-past

'Junko was in her room when Satoshi came' (episodic)

b. $\exists \mathrm{t}^{\prime}\left[\mathrm{t}^{\prime}<\mathrm{s}^{*} \&\right.$ in-her-room(junko)(t') \& $\exists \mathrm{t}^{\prime \prime}\left[\mathrm{t} "<\mathrm{s}^{*} \&\right.$ come(satoshi) $\left.\left.\left(\mathrm{t}^{\prime \prime}\right) \& \mathrm{t} "=\mathrm{t}^{\prime}\right]\right]$

\subsubsection{A present tense variable and the quantificational interpretation of} when-clauses

Given the contrast we have established between past and present tense in Japanese in terms of quantificational force, we predict that it is the present tense that will be bound by adverbs of quantification, and this corresponds with the interpretation of (34a). In the analysis given in (34c), the whenclause functions as a restrictor of a covert adverb of quantification. The adverb binds the present tense variable in the adjunct:

a. [Satoshi-ga kuru toki] Junko-wa heya-ni ita S-nom come-pres when J-top room-at be-past 'Junko was in her room whenever Satoshi came'

b. $\exists \mathrm{t}\left[\mathrm{t}<\mathrm{s}^{*} \& \forall \mathrm{t}^{\prime} \mathrm{t}^{\prime} \subseteq \mathrm{t} \&\right.$ come $($ satoshi $)\left(\mathrm{t}^{\prime}\right)$ $\rightarrow \exists \mathrm{t}^{\prime}[\mathrm{t} " \subseteq \mathrm{t}$ ' \& in-her-room(junko)(t")]]]

c. $\quad \mathrm{CP}: \exists \mathrm{t}\left[\mathrm{t}<\mathrm{s}^{*} \& \forall \mathrm{t}^{\prime}\left[\mathrm{t}^{\prime} \subseteq \mathrm{t} \&\right.\right.$ come(satoshi) $\left(\mathrm{t}^{\prime}\right)$

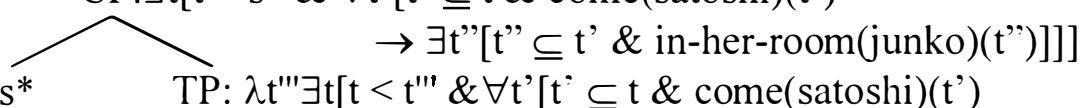

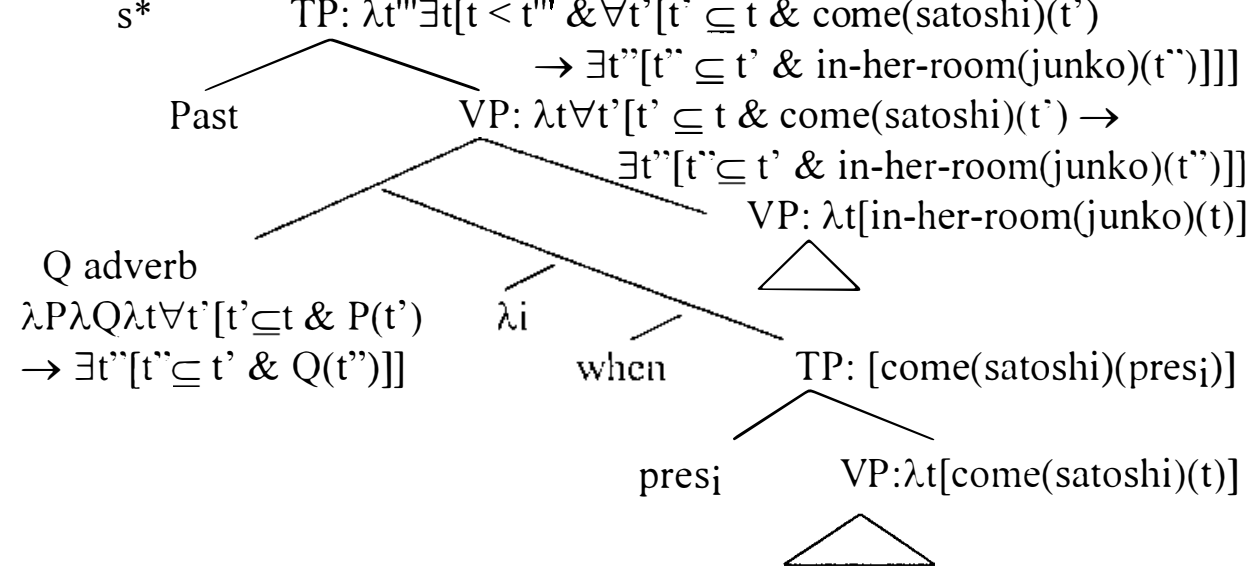

In our analysis the present tense in (34) behaves in a manner that is similar to the present tense in (30). In both cases it is a variable that is bound by a quantificational element. 


\subsubsection{Some more examples}

Our discussion of the quantificational contrast between past and present in Japanese remains unfortunately sketchy. However there are other examples that suggest it is a promising approach. At this point we can only make the observation, the derivation of the results remains a topic for further research.

In (35a), where the present tense is used in the relative clause, the embedded clause event is understood as habitual. There is a place where Satoshi habitually parked his car and Junko lost her key there.

(35) a. Junko-wa [Satoshi-ga kuruma-o tyusyasuru] basho-de kagi-o

J-top S-nom car-acc park-pres place-at key-acc

nakusita

loose-past

'Junko lost her key where Satoshi usually parked his car'

When the past tense is used in the relative clause (35b). the event is understood episodically. The speaker of the sentence has a particular past event of Satoshi's parking in mind.

b. Junko-wa [Satoshi-ga kuruma-o tyushasita] basho-de kagi-o

J-top S-nom car-acc park-past place-at key-acc

nakusita

loose-past

'Junko lost her key where Satoshi parked his car'

The contrast between past and present in (36) is not temporal either. In both cases we are speaking about people who in the past came every week. The use of a present tense relative clause (36a) tells us that these visits were a habit. while a past tense (36b) tells us that the pattern of the visits was accidental.

(36) a. [Maisyuu kuru hito]-wa Hanako-to Taroo desita every week come-pres people-top Hanako-and Taroo be-past 'Those who had a habit of coming every week were Hanako and Taroo'

b. [Maisyuu kita hito]-wa Hanako-to Taroo desita every week come-past people-top Hanako-and Taroo be-past

'Those who happened to come every week were Hanako and Taroo'

(examples from Kuno [1973]) 


\section{Concluding remarks}

We have argued that tense in TACs is not semantically in the scope of the matrix tense. Differences in tense distribution between English, Polish, and Japanese arise from differences regarding the structure of TACs, and are independent of the presence or absence of an SOT-rule.

Regarding the distribution of tense in Japanese before- and afterclauses, we have suggested that the restrictions are due to differences in quantificational strength between Japanese past and present tense. The interpretation of when- clauses has provided evidence in favour or such a distinction.

\section{Endnotes}

* We would like to thank Angelika Kratzer and Kyle Johnson for their help throughout our research. We are also grateful to the following people for comments, advice, and data: Jenny Doetjes, Arantzazu Elordieta, Ania Lubowicz, Anita Nowak, Toshiyuki Ogihara, Norvin Richards, Johan Rooryck, Grazyna Rowicka, Junko Shimoyama, Satoshi Tomioka, and the members of the Umass Semantics Reading Group.

I Present tense events in Japanese can receive a future orientated interpretation:

(i) Junko-wa asita Berlin-ni kuru.

J.-top tomorrow Berlin-to come-pres

'Junko will come to Berlin tomorrow'

2 The reader is referred to Ogihara [1996: 183] for a detailed working out of the lexical entries of Japanese before and after.

- Only the examples with before- clauses are relevant to the point made by Ogihara. For the sake of completeness we illustrate below the behaviour of tense in Polish after-clauses, where the tense pattern is the same as in before-clauses:

(i) a. Ania przyszła na przyjẹcie po tym jak Marcin wyszedł. Ania prf-come-past to party after this how Marcin prf-leave-past 'Ania came to the party after Marcin left'

b. *Ania przyszła na przyjẹcie po tym jak Marcin wychodzi.

Ania prf-come-past to party after this how Marcin prf-leave-pres

${ }^{+}$In this paper we will not be concerned with semantic contrasts between before and after, and we will leave the discussion at this very superficial level. The reader is referred to the authors mentioned above and to Ogihara [1995b] for further details

' In any case, it is encouraging to note that a distinction would not be idiosyncratic to Japanese. In (some dialects of) Spanish there is a contrast between before and afler regarding the choice of subjunctive versus indicative 
mood. Cross-linguistic variation regarding binding possibilities of before and affer could throw light on Japanese before, but it is outside the scope of our paper.

\section{References}

Anscombe, G. 1964. Before and After. The Philosophical Review 73. 3-24.

Enç, M. 1987. Anchoring Conditions for Tense. Linguistic Inquiry 18.633-657

Geis. M. 1970. Adverbial Subordinate Clauses in English. Ph.D dissertation, MIT

Heim. I. and A. Kratzer 1997. Semantics in Generative Grammar. Blackwell.

Johnston, M. 1994. The Syntax and Semantics of Adverbial Adjuncts, $\mathrm{PhD}$. dissertation. University of California at Santa Cruz.

Kratzer, A. 1986. Conditionals. CLS 22. 1-15.

Kratzer, A. 1995. Stage-level and Individual-level Predicates. The Generic Book.

Kuno. S. 1973. The Structure of the Japanese Language. MIT Press, Cambridge, MA.

Ladusaw, W. 1979. Polarity Sensitivity as Inherent Scope Relations. Ph.D. dissertation,

Landman, F. 1991. Structures for Semantics. Kluwer Academic Publishers. Dordrecht.

Larson, R. 1990. Extraction and Multiple Selection in PP. The Linguistic Review: 7, 169-182.

Lewis. D. 1975. Adverbs of Quantification. In E. Keenan (ed.) Formal Semantics of Natural Language. 3-15. Cambridge University Press. Cambridge, MA.

Ogihara, T. 1989. Temporal Reference in English and Japanese. Ph.D. dissertation, University of Texas, Austin

Ogihara, T. 1994. Adverbs of Quantification and Sequence-of-Tense Phenomena. SALT IV. 251-267. Cornell University, Ithaca. N.Y.

Ogihara, T. 1995a. The Semantics of Tense in Embedded Clauses. Linguistic Inquiry 26. 663-679.

Ogihara. T. 1995b. Non-factual before and Adverbs of Quantification. SALT V. 273-291. Cornell University, Ithaca, N.Y.

()gihara. T. 1996. Tense, Attitudes, and Scope. Kluwer Academic Publishers. Dordrecht.

Partee. H.B. 1973. Some Structural Analogy between Tenses and Pronouns in English. The Journal of Philosophy 7, 243-286.

Prior. A.N. 1967. Past, Present and Future. Clarendon Press, Oxford.

Rothstein, R.A.. 1993, Polish, in Cormrie, B. \& G. Corbett, (eds.). The Slaronic Languages, Routledge. London, 686-758. 